\title{
Comparative Analysis of Photovoltaic Generating Systems Using Particle Swarm Optimization and Cuckoo Search Algorithms under Partial Shading Conditions
}

\author{
Rahul Wilson Kotla*, Srinivasa Rao Yarlagadda \\ Department of Electrical and Electronics Engineering, Vignan's Foundation for Science Technology and Research, Vadlamudi, \\ Guntur, AP-522213, India
}

Corresponding Author Email: krw_eeep@vignanuniversity.org

https://doi.org/10.18280/jesa.540104

Received: 2 November 2020

Accepted: 30 January 2021

\section{Keywords:}

cuckoo search algorithm, PV generating system, partial shading conditions, particle swarm optimization algorithm

\begin{abstract}
The energy demand on the electricity grids increased rapidly due to that non-conventional energy sources (NCES) like PV, wind power plants are encouraged to establish and operate with the grid. Out of the available NCES, Photovoltaic generating systems (PVGS) are widely penetrated to the grids. As the output power extracted from the PVGS is non-linear, it becomes fluctuating depending on the available Irradiance $(\mathrm{G})$, Temperature (T), and partial shading conditions (PSC). So, there is a need for the development of maximum power point tracking (MPPT) algorithms in the PVGS for maximizing the output power and minimizing the fluctuations. In this article, a comparative analysis of two advanced MPPT algorithms namely particle swarm optimization algorithm (PSOA) and cuckoo search algorithm (CSA) is presented. These two algorithms are used to control the duty cycle of the boost converter to maximize the PVGS output power. The proposed design is modeled using Matlab/Simulink software and the results were obtained and analyzed.
\end{abstract}

\section{INTRODUCTION}

Nowadays, the electricity grids are overloaded due to the increased power consumption by the industrial as well as the domestic consumers. For this reason, the generating capacities of the existing power plants should be increased, or else new power plants are to be installed. Due to the limitations of transmission line capacities, new power plants are encouraged to install. While conventional energy sources are decreased day to day, NCES are encouraged to establish and operate with the existing grids. Among all the available NCES, PVGS is the widely used source due to its availability and ecofriendly nature. The total NCES installed in the world up to the year 2019 as per the article of Renewable capacity statistics 2020 by the International renewable energy agency is $2537 \mathrm{GW}$ and the solar energy capacity is $586 \mathrm{GW}$ [1].

The PVGS systems comprise several PV arrays which are connected in parallel and series structures depending on the requirement of output voltage and current. The basic design modeling of the PV array is discussed by Kotla et al. [2, 3]. The major drawback of PVGS is having the fluctuating output power due to $G$ and $T$ variations throughout the day, due to this reason a charge controller comes into existence that contains the MPPT algorithm to maximize the PVGS power. The most widely used MPPT algorithms are discussed by Wilson et al. [4, 5], which only works for the single peak operating point in the P-V curve. For the PSC case where there will be multiple peaks that occur in the system [6, 7]. Identifying the global peak from the multiple peaks is not possible with the basic MPPT algorithms, to identify the global peak under PSC advanced MPPT algorithms like PSOA and CSA are used [8]. To know the global peak the complete characteristics of the PV array and its connection structures should be analyzed, the different connection structures of PV arrays are discussed by Wilson [9, 10].

Optimization algorithms play a major role in many fields of engineering. We have viewed different kinds of evolutionary algorithms advanced to solve optimization problems, such as estimation of distribution algorithms (EDA), genetic algorithm (GA), firefly algorithm (FA), differential evolution (DE), ant colony optimization (ACO), artificial bee colony $(\mathrm{ABC})$, flower pollution algorithm (FPA), PSOA, and CSA [11]. Among them, the performance of PSOA and CSA has been carefully studied by many researchers.

Moreover, CSA has been proved to be an efficient algorithm when applying to solve real-world problems. In paper [12], the proposed system uses CSA for solving structural design optimization problems. The CSA is applied to the structural design optimization of a vehicle component to illustrate how the present approach can be applied for solving structural design problems. The performance of CSA with that of PSOA, differential evolution, and artificial bee colony on global optimization problems is discussed by Civicioglu [13].

Although the above evolutionary algorithms (EA) work satisfactorily regarding MPPT, there is still a need to develop modern EAs. Recently, CSA has been used to solve the load frequency issues, and it shows very satisfactory results compared to the genetic algorithm and PSOA [14-16]. This encourages the authors to develop a modern EA based on CSA to solve MPPT issues also.

The significance of this paper is that PSOA directly uses the global best solution of the population to determine new positions for the particles at each iteration, and the agents of the CSA do not directly use this information but the global best solution in the CSA is stored at each iteration. Therefore, for the PSOA component, the neighborhood information is taken into the new population to improve the diversity of the algorithm. In the second component, two new methods are 
utilized to balance the exploitation and exploration of the algorithm through a random probability rule.

This paper uses $250 \mathrm{~W}$ Taiwan semiconductor Manufacturing TS-250P4-AD panels to design an array, the maximum capacity of the PVGS is $1000 \mathrm{~W}$. This paper model the PVGS along the PSOA and CSA MPPT to maximize the output power of the PVGS. This paper shows the results of PSOA and CSA MPPT algorithms to work well with the global peak situations at the time of PSC conditions in the PVGS to reduce the power losses in the system and the results were compared and analyzed.

The rest of the paper is organized as follows: Section 2 presents the connection structures of SPV arrays, section 3 presents the operation of PVGS under PSC, section 4 introduces the description of PSOA, section 5 introduces the description of CSA, section 6 presents the simulation results of the proposed system and section 7 concludes the article.

\section{CONNECTION STRUCTURES OF SPV ARRAYS}

The Different connection structures of SPV arrays are classified in ref. [9] as follows:

- Series connected structure (SCS).

- Parallel connected structure (PCS).

- Cross Tied structure (CTS).

Out of the Available connection structures, in this paper, the SCS connection structure of PVGS is used for the simulations by referring to the analysis of different connection structures which was presented by Wilson and Rao [9].

The basic block diagram representation of the SCS connection structure of PVGS is shown in Figure 1. The SPV arrays are allied in series to get a single current to flow in this SCS and output loads should be placed across both terminals. This structure is the simplest as there are no cross-links among adjacent columns having an increased voltage and the same current as that of a single SPV array. The block diagram of SCS $4 \times 1$ in structure is shown in Figure 1. The simplicity of the connection is one of the few benefits of SCS. Out of all the structures of the SPV array, SCS is having moderate performance characteristics with bypass diodes.

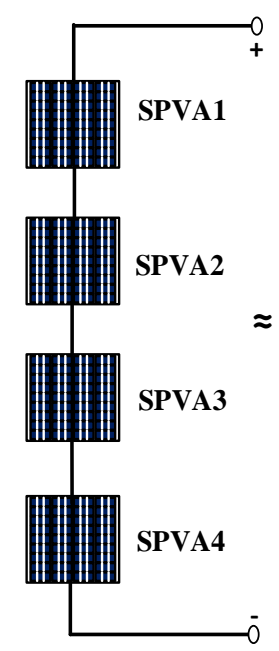

Figure 1. Connection structure of SCS of the PVGS

In the PCS type of SPV array has 4 modules are used all the positive ends are linked at one end to form a positive terminal and all negative terminals are linked at one end to form a negative terminal for which loads are placed among them. The PCS gives rise to increased current at the output end and the same voltage as that of a single SPV array. The block diagram of PCS of $4 \times 1$ in structure is shown in Figure 2.

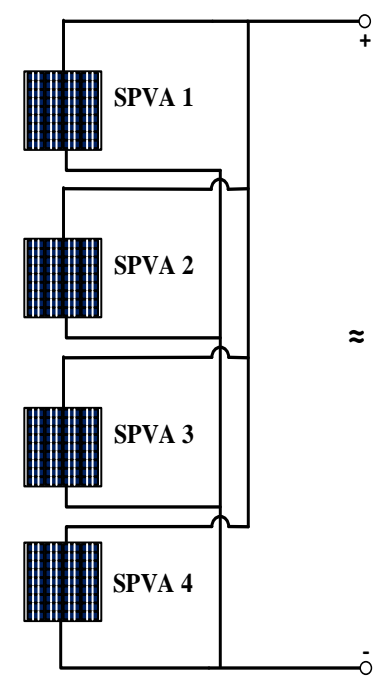

Figure 2. Connection structure of PCS of the PVGS

In CTS all the SPV arrays are allied in parallel to which the row they exist and in series with the other rows. Every node in the CTS is connected to all the SPV arrays in the row and series to all other rows. The block diagram of CTS of $2 \times 2$ in structure is shown in Figure 3.

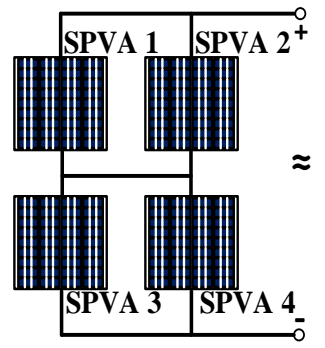

Figure 3. Connection structure of CTS of the PVGS

\section{OPERATION OF PVGS UNDER PSC}

The basic connection styles for Modelling the PVGS under PSC are mainly classified into three types. The first one is the parallel tied modules, the second one is the series tied modules and the last one is the cross-tied modules. Out of three connection styles series tied modules are highly affected under PSCs as discussed in the papers [9, 16, 17]. For this reason, in this article parallel-tied modules are considered for extracting the electrical characteristics of the PVGS.

The PVGS is formed by connecting four modules in series as shown in Figure 1 and The output electrical characteristics of this connection are shown in Figure 4, which shows the multiple peaks that occur under PSC conditions. The simulation circuit for SCS is shown in Figure 5.

For analyzing the effects of PSC and for extracting the electrical characteristics of PVGS three case studies have been taken by varying the $\mathrm{G}$. For case study 1 the value of $\mathrm{G}$ and $\mathrm{T}$ are taken at standard test conditions (STC) i.e., $\mathrm{G}$ is taken as $1000 \mathrm{~W} / \mathrm{m}^{2}$ for all the PV modules and $\mathrm{T}$ is kept constant at 
$25^{\circ} \mathrm{C}$. For case study 2 the values of $\mathrm{G}$ are taken as $1000 \mathrm{~W} / \mathrm{m}^{2}$, $800 \mathrm{~W} / \mathrm{m}^{2}, 600 \mathrm{~W} / \mathrm{m}^{2}, 400 \mathrm{~W} / \mathrm{m}^{2}$ for $4 \mathrm{PV}$ modules respectively, these values are considered using irregular conditions $1\left(\mathrm{IC}_{1}\right)$ which represents PSC on the PV panels, and the $\mathrm{T}$ is taken as $25^{\circ} \mathrm{C}$, and similarly, for the case study 3 also irregular conditions $2\left(\mathrm{IC}_{2}\right)$ are considered and the $\mathrm{G}$ values are $750 \mathrm{~W} / \mathrm{m}^{2}, 500 \mathrm{~W} / \mathrm{m}^{2}, 250 \mathrm{~W} / \mathrm{m}^{2}, 50 \mathrm{~W} / \mathrm{m}^{2}$, and the $\mathrm{T}$ is taken as $25^{\circ} \mathrm{C}$.

From the characteristics of PVGS multiple peaks occurs in the P-V curves, and for identifying the global peak from the multiple peaks advanced MPPT algorithms like PSOA and CSA are used in this paper.

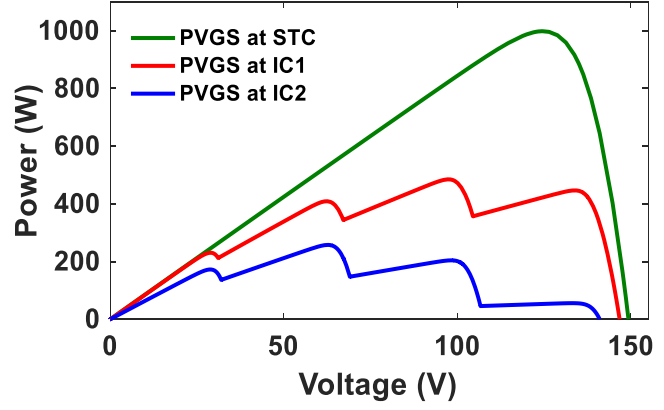

(a)

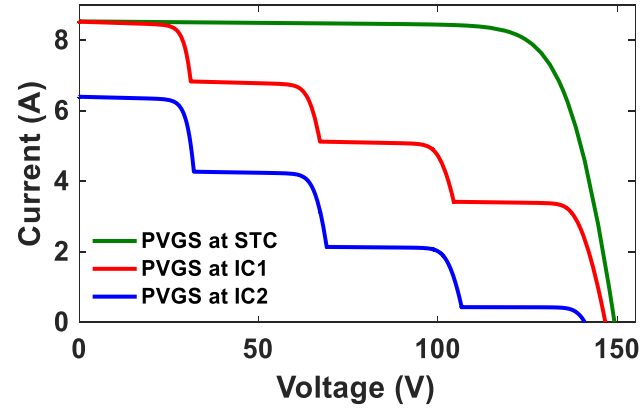

(b)

Figure 4. Electrical characteristics of PVGS

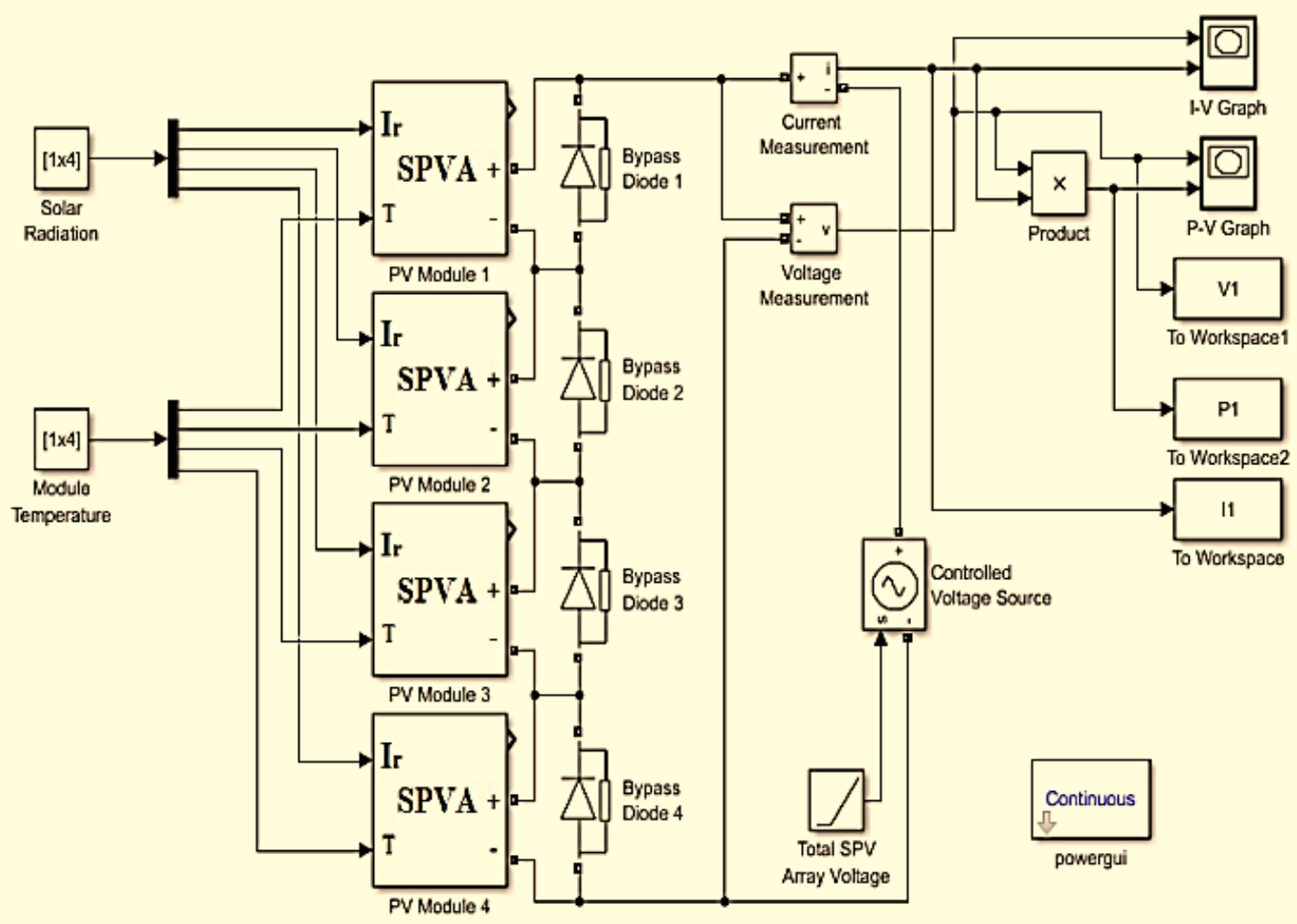

Figure 5. Simulation circuit of series tied modules in the PVGS

\section{PARTICLE ALGORITHM \\ SWARM \\ OPTIMIZATION}

PSOA was developed based on the mammalian swarm actions, in which each mammalian was taken as a particle to get the objective function globally [15]. In this algorithm, by using (1) and (2) the swarm velocity is identified and used to adjust the current position (CP) [8].

$$
\begin{aligned}
& v_{i, j}^{1+K}=\omega_{o} v_{i, j}^{k}+r_{1} c_{1, j}\left(G_{b e s t i, j}^{k}-C P_{i, j}^{k}\right) \\
& +r_{2} c_{2}\left(P_{b e s t i, j}^{k}-C P_{i, j}^{k}\right)
\end{aligned}
$$

$$
C P_{i, j}^{1+K}=C P_{i, j}^{k}+v_{i, j}^{k+1}
$$

where,

$\mathrm{c} 1, \mathrm{c} 2$, and $\mathrm{r} 1, \mathrm{j}, \mathrm{r} 2, \mathrm{j}=$ random values taken from 0 to 1 $\mathrm{c} 1, \mathrm{c} 2=$ acceleration constants

$\mathrm{r} 1, \mathrm{j}, \mathrm{r} 2, \mathrm{j}=$ random numbers

$\mathrm{i}=\mathrm{i}^{\text {th }}$ particle in the population $(1,2, \ldots ., \mathrm{NP})$

$\mathrm{j}=\mathrm{j}^{\text {th }}$ particle in the population $(1,2, \ldots ., \mathrm{D})$

$\mathrm{NP}=$ size of the population

$\mathrm{D}=$ dimension of the searching space

$\omega_{\mathrm{o}}=$ weight of Inertia

$\mathrm{P}_{\text {best }}=$ Personal best

$\mathrm{G}_{\text {best }}=$ Global best. 


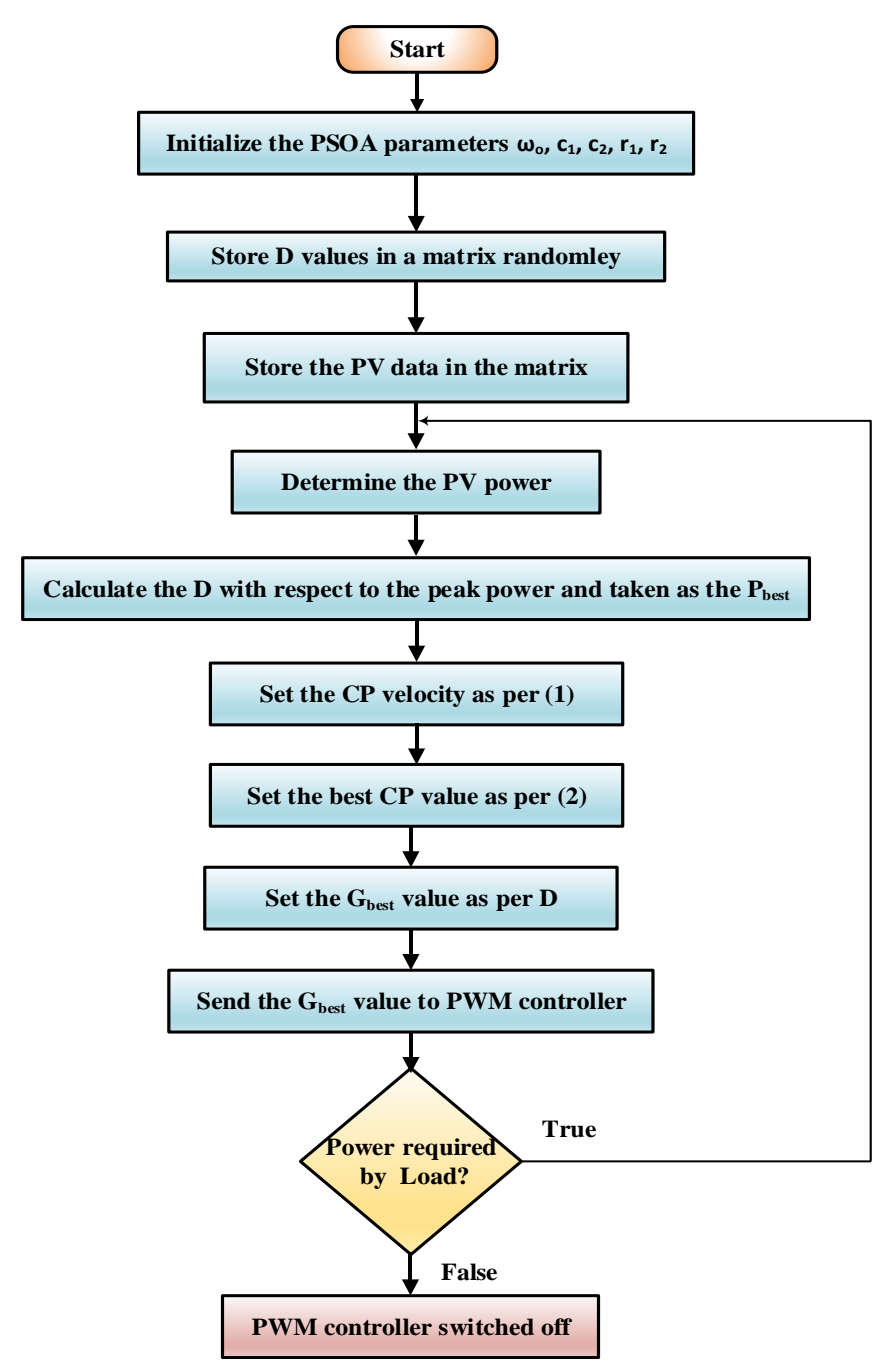

Figure 6. Working flowchart of PSOA

Mainly, PSOA works to identify the $\mathrm{P}_{\text {best }}$ of duty cycle (D) and it will be stored in the PWM box. This algorithm initializes the value of $\mathrm{D}$ randomly and stores it in a matrix form. The algorithm runs if the system requires power to the load. The flowchart for the PSOA is shown in Figure 6.

\section{CUCKOO SEARCH ALGORITHM}

CSA was developed based on the reproduction parasitism of cuckoo, the optimization function was discussed in the ref. [16]. In this algorithm, by using (3) and (4) the levy flights are used to update the D in terms of gamma function $(\gamma)$ [8].

$$
\begin{gathered}
\delta=\left[\frac{\gamma(\beta+1) \times \sin \pi \times\left(\frac{\beta}{2}\right)}{\gamma\left(\frac{\beta+1}{2}\right) \times \beta \times 2^{\frac{\beta-1}{2}}}\right]^{\frac{1}{\beta}} \\
C P_{i}^{1+K}=C P_{i}^{k}+\alpha \times G_{\text {best }} \times \frac{|u|}{|v|^{\frac{1}{\beta}}}
\end{gathered}
$$

where,

$\mathrm{u}=$ uniformly distributed matrices of value 1 ,

$\mathrm{v}=$ uniformly distributed matrices of value $\delta$.

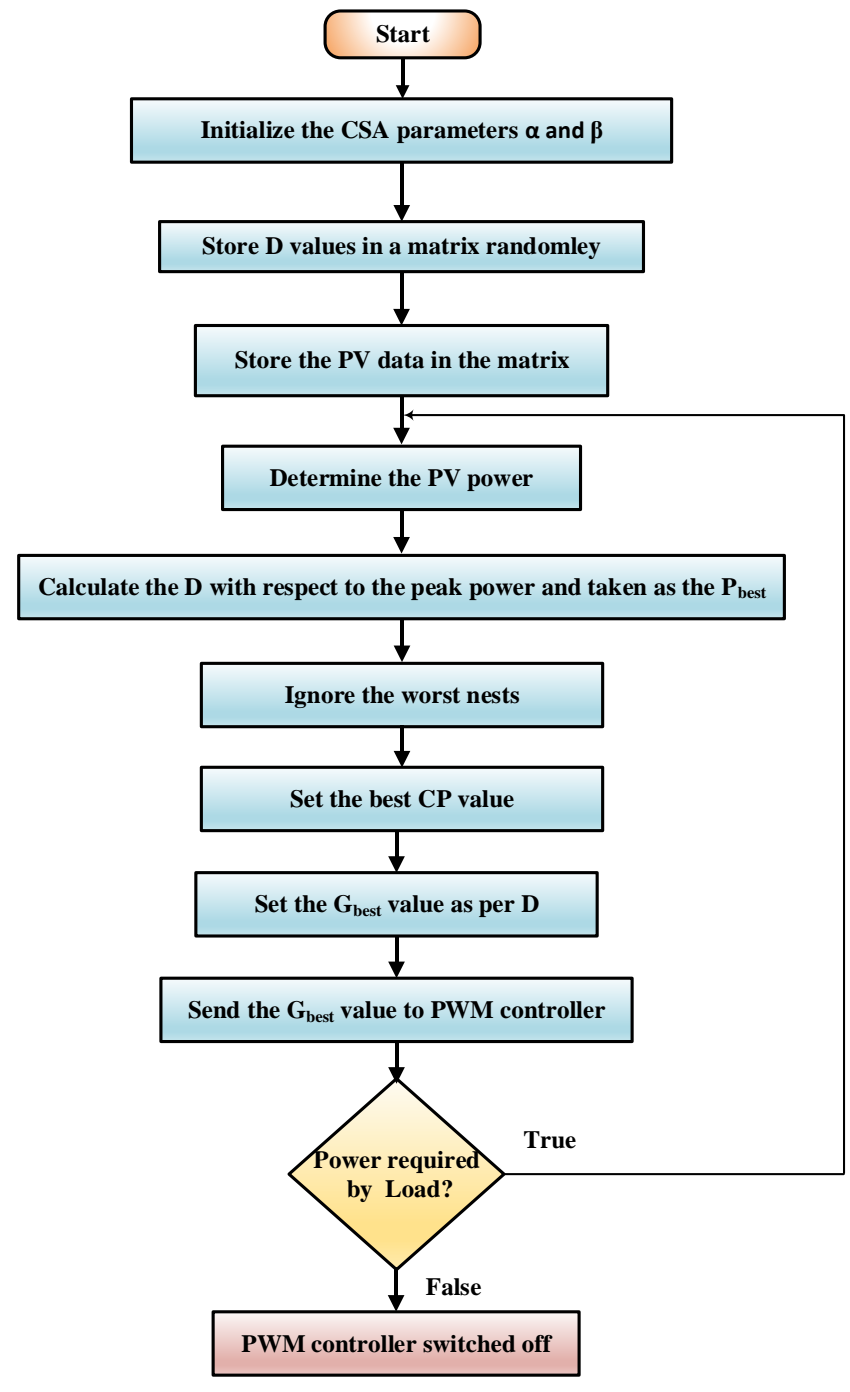

Figure 7. Flowchart of CSA

Mainly, CSA works to identify the $\mathrm{G}_{\text {best }}$ value of D and it will be stored in the PWM box. This algorithm initializes the value of $\mathrm{D}$ randomly and stores it in a matrix form. The algorithm runs if the system requires power to the load and ignores the worst solutions and replaces them with new nests. The flowchart for the CSA is shown in Figure 7.

\section{SIMULATION RESULTS}

The simulation circuit of the designed PVGS system with PSOA and CSA MPPT algorithms is shown in Figure 8 and Figure 9, respectively. The simulation parameters for the single PV module system are presented in Table 1.

Table 1. Specifications of single PV module

\begin{tabular}{cc}
\hline Parameters & Ratings \\
\hline Module Power & $250 \mathrm{~W}$ \\
Open circuit voltage, $\mathrm{V}_{\mathrm{oc}}$ & $37.32 \mathrm{~V}$ \\
Short circuit current, $\mathrm{I}_{\mathrm{sc}}$ & $8.5 \mathrm{~A}$ \\
Cells per module & 60 \\
Voltage at MPP, $\mathrm{V}_{\mathrm{mp}}$ & $31.14 \mathrm{~V}$ \\
Current at MPP, $\mathrm{I}_{\mathrm{mp}}$ & $8.03 \mathrm{~A}$ \\
\hline
\end{tabular}




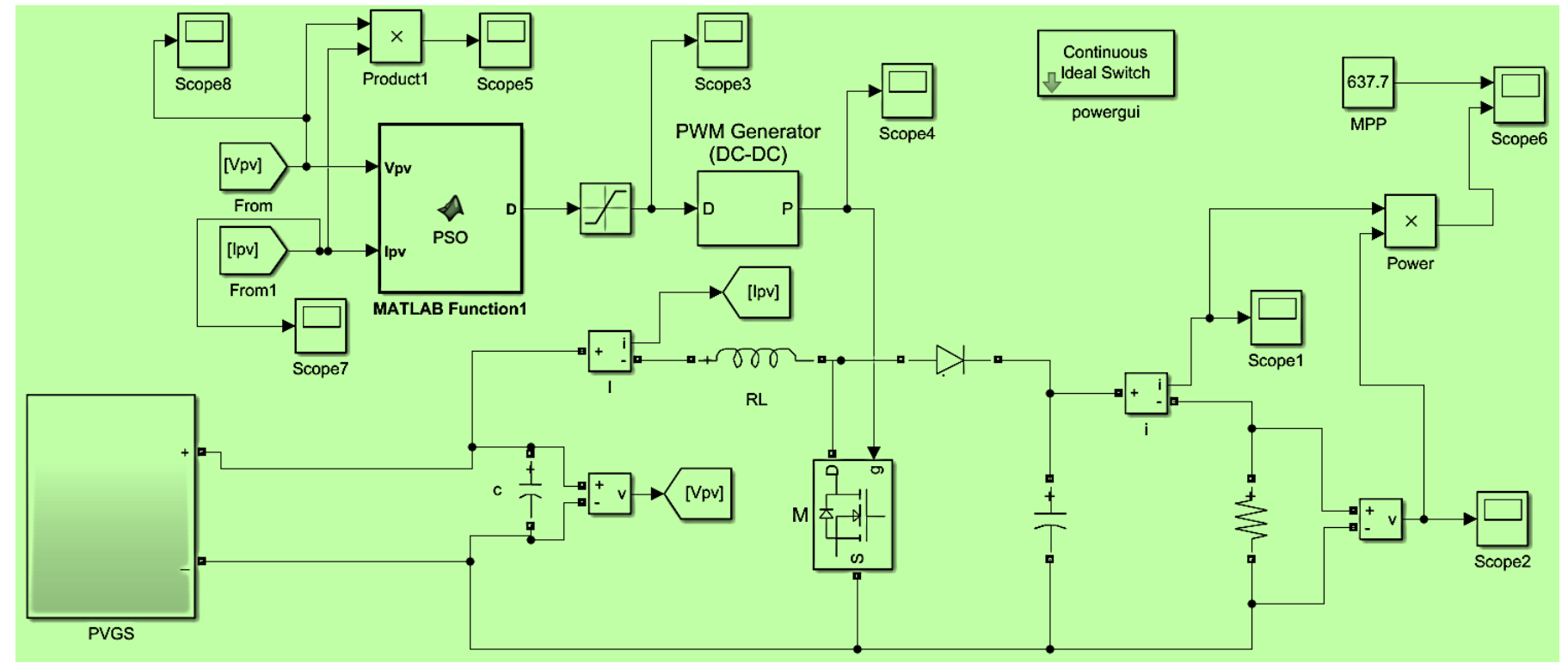

Figure 8. Simulation circuit of PSOA

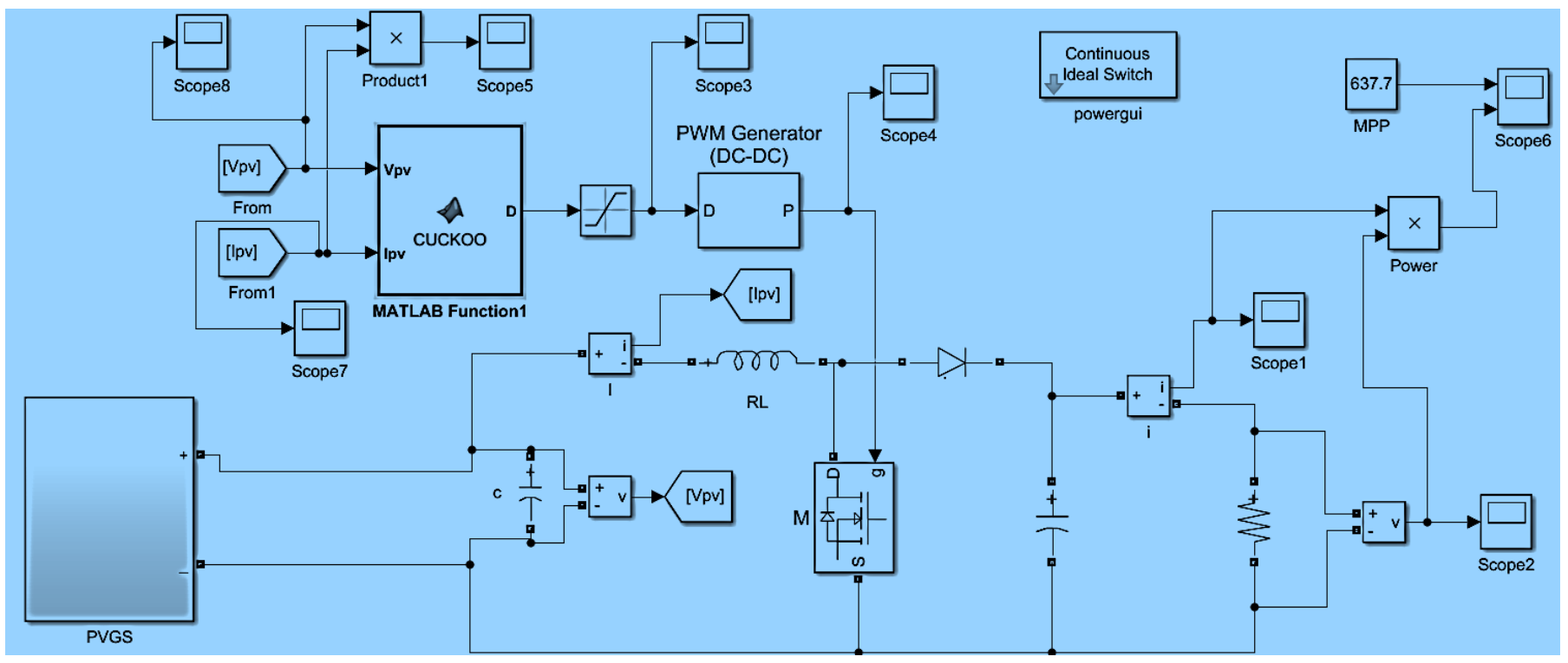

Figure 9. Simulation circuit of CSA

For result verifications, PSC conditions are considered and the irradiance values are taken as $500 \mathrm{~W} / \mathrm{m}^{2}, 1000 \mathrm{~W} / \mathrm{m}^{2}, 800$ $\mathrm{W} / \mathrm{m}^{2}, 1000 \mathrm{~W} / \mathrm{m}^{2}$ on the 4 modules, respectively. The simulation results of PSOA show that the voltage and current waveforms have some oscillations, and it takes 1 to $1.5 \mathrm{sec}$ to track the MPP point. Figure 10 shows the simulation results of PVGS with PSOA. Figure 10 (a) represents the voltage of the system, Figure 10 (b) represents the current of the system and Figure 10 (c) represents the power output of the system operating under PSOA.

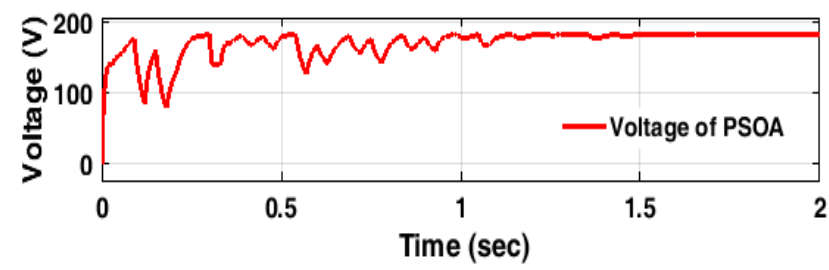

(a)

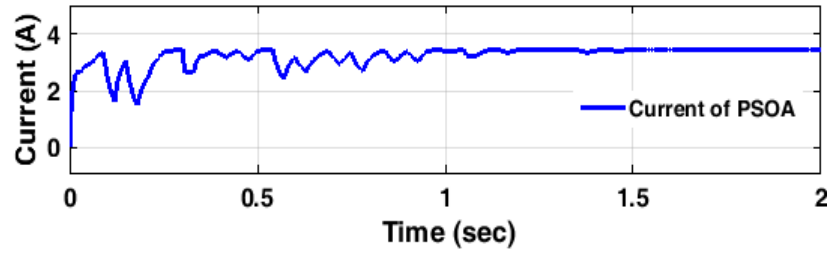

(b)

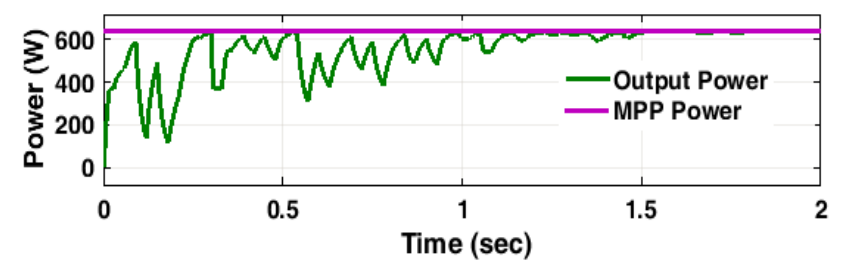

(c)

Figure 10. Simulation results of PVGS using PSOA. (a) Voltage (b) Current (c) Output power vs MPP power 


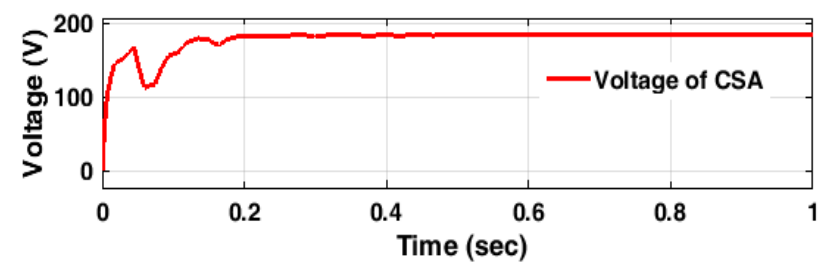

(a)

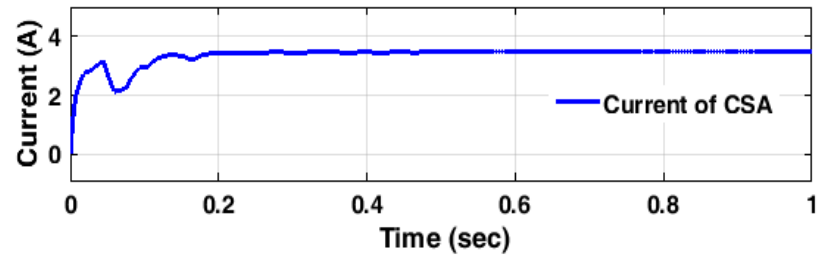

(b)

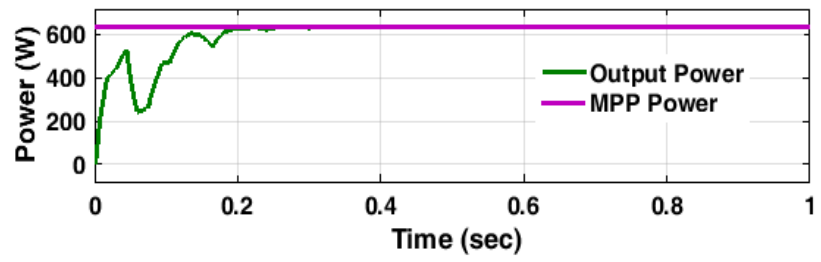

(c)

Figure 11. Simulation results of PVGS using CSA. (a) Voltage (b) Current (c) Output power vs MPP power

Table 2. Specifications of single PV module

\begin{tabular}{ccc}
\hline \multirow{2}{*}{ Parameters } & \multicolumn{2}{c}{ MPPT Algorithms } \\
\cline { 2 - 3 } & PSOA & CSA \\
\hline Initial starting speed (msec) & $250-600$ & $100-300$ \\
Power fluctuations & High & Moderate \\
Partial shading capability & Yes & Yes \\
Transient state oscillations & High & Moderate \\
Steady state oscillations & 0.0005 & 0.000008 \\
Turning parameters required & 3 & 2 \\
Complexity & Easy & Moderate \\
\hline
\end{tabular}

Similarly, the simulation results of CSA show that the voltage and current waveforms have fewer oscillations as compared with the PSOA, and it takes around $0.2 \mathrm{sec}$ to track the MPP point. Figure 11 shows the simulation results of PVGS with CSA. Figure 11 (a) represents the voltage of the system, Figure 11 (b) represents the current of the system, and Figure 11 (c) represents the power output of the system operating under CSA.

As compared with the results of PSOA with the CSA, CSA has a better tracking speed, better performance, and fewer oscillations in the power which was given in Table 2.

\section{CONCLUSIONS}

This article presents the design modeling of the PVGS system with advanced MPPT algorithms for PSC. The electrical characteristics of the PVGS system are extracted under different operating conditions using three case studies, which show the multiple peaks that occur in the P-V curve when the system is exposed to the PSC. For effective tracking under PSC conditions in this article PSOA and CSA algorithms were analyzed using different values of $\mathrm{G}$ and $\mathrm{T}$. From the results is clear that CSA has better performance, fasttracking, fewer oscillations in the output power, and leads to high-efficiency output when compared with the PSOA under
PSC. In this article, the optimization techniques which were used are to solve the MPPT applications. Further, these algorithms can be improved to solve other optimization problems such as constrained optimization problems.

\section{REFERENCES}

[1] Renewable Capacity Statistics. (2020). International Renewable Energy Agency (IRENA). Retrieved from https://www.irena.org/publications/2020/Mar/Renewabl e-Capacity-Statistics-2020, accessed on 10 Jan. 2021.

[2] Kotla, R.W., Yarlagadda, S.R. (2020). Mathematical modelling of SPV array by considering the parasitic effects. SN Applied Sciences, 2(50): 2020. https://doi.org/10. 1007/s42452-019-1861-x

[3] Kotla, R.W., Yarlagadda, S.R. (2020). Modelling and control of a three phase PVGT system. IEEE India Council International Subsections Conference (INDISCON), pp. 96-101. https://doi.org/10.1109/INDISCON50162.2020.00031

[4] Wilson, K.R., Rao, Y.S. (2019). Comparative analysis of mpptt algorithms for pv grid tied systems: A review. In 2nd IEEE International Conference on Intelligent Computing, Instrumentation and Control Technologies (ICICICT), 1: 1105-1110. https://doi.org/10.1109/ICICICT46008.2019.8993148

[5] Kotla, R.W., Yarlagadda, S.R. (2020). Grid tied solar photovoltaic power plants with constant power injection maximum power point tracking algorithm. Journal Européen des Systèmes Automatisés, 53(4): 567-573. https://doi.org/10.18280/jesa.530416

[6] Ibrahim, R., Aboe, I., Obukhov, S. (2019). Application of cuckoo search algorithm for global maximum power point tracking of PV under partial shading. Int. Youth Conf. Radio Electron. Electr. Power Eng., 1: 1-6. https://doi.org/10.1109/REEPE.2019.8708788

[7] Ahmed, J., Salam, Z. (2018). An enhanced adaptive P\&O MPPT for fast and efficient tracking under varying environmental conditions. IEEE Trans. Sustain. Energy, 9(3):

$1487-1496$ https://doi.org/10.1109/TSTE.2018.2791968

[8] Abo, E.K., Farag, A., Abdelshafy, M., Abdelaziz, A.Y. (2020). MPPT-based particle swarm and cuckoo search algorithms for PV systems. Modern Maximum Power Point Tracking Techniques for Photovoltaic Energy Systems, Springer, Cham, 379-400. https://doi.org/10.1007/978-3-030-05578-3_14

[9] Wilson, K.R., Rao Y.S. (2019). Effects of partial shading on different structures of solar photovoltaic arrays. Journal of Mechanics of Continua and Mathathematical Sciences, 14(6): 845-854. https://doi.org/10.26782/jmcms.2019.12.00062

[10] Ramaden, A.L., Smadi, I.A. (2019). Partial shading detection and global mppt algorithm for pv system. IEEE Jordan Int. Jt. Conf. Electr.Eng. Inf. Technol., pp. 135140. https://doi.org/10.1109/JEEIT.2019.8717442

[11] Li, X.T., Yin, M.H. (2016). A particle swarm inspired cuckoo search algorithm for real parameter optimization. Soft Computing, 20: 1389-1413. https://doi.org/10.1007/s00500-015-1594-8

[12] Durgun, I., Yildiz, A.R. (2012). Structural design optimization of vehicle components using cuckoo search algorithm. Mater Test, 54(3): 185-188. https://doi.org/10.3139/120.110317 
[13] Civicioglu, P. (2013). Backtracking search optimization algorithm for numerical optimization problems. Applied Mathematics and Computation, 219(15): 8121-8144. https://doi.org/10.1016/j.amc.2013.02.017

[14] Wahab, A.B., Nadhir, M., Nefti, M.S., Atyabi, A. (2015). A comprehensive review of swarm optimization algorithms. PLOS ONE, 10(5): e0122827. https://doi.org/10.1371/journal.pone.0122827

[15] Abdelshafy, A.M., Hassan, H., Jurasz, J. (2018). Optimal design of a grid-connected desalination plant by renewable energy resources using a hybrid PSO-GWO approach. Energy ConvManag, 173: 331-347. https://doi.org/10.1016/j.enconman.2018.07.083

[16] Abdelaziz, A.Y., Ali, E.S. (2016). Load frequency controller design via artificial cuckoo search algorithm. Elect Power Comp Syst., 44(1): 90-98. https://doi.org/10.1080/15325008.2015.1090502

[17] Darmini, M., Sunitha, K. (2017). Comparison of solar PV array configuration methods under different shading patterns. Proc. IEEE Int. Conf. Technol. Adv. Power Energy Explor. Energy Solut. an Intell. Power Grid, TAP Energy, $\mathrm{pp}$ $1-4$. https://doi.org/10.1109/TAPENERGY.2017.8397300

\section{NOMENCLATURE}

$\begin{array}{ll}\omega_{\mathrm{o}} & \text { Weight of Inertia } \\ \mathrm{P}_{\text {best }} & \text { Personal best } \\ \mathrm{G}_{\text {best }} & \text { Global best } \\ \mathrm{G} & \text { Irradiance, } \mathrm{W} / \mathrm{m}^{2} \\ \mathrm{D} & \text { Duty cycle } \\ \mathrm{T} & \text { Temperature, }{ }^{\circ} \mathrm{C} \\ \mathrm{s} & \text { Constant lies between } 0.7 \text { to } 0.8 \\ \mathrm{~V}_{\mathrm{oc}} & \text { Open circuit voltage, volts } \\ \mathrm{I}_{\mathrm{sc}} & \text { Short circuit current, Amps } \\ \mathrm{V}_{\mathrm{mp}} & \text { Maximum voltage, volts } \\ \mathrm{I}_{\mathrm{mp}} & \text { Maximum current, Amps } \\ \mathrm{NOCT} & \text { Nominal operating cell temperature } \\ \mathrm{v} & \text { Uniformly distributed matrices of } \delta \\ \mathrm{u} & \text { Uniformly distributed matrices of } 1 \\ \alpha \text { and } \beta & \text { CSA parameters } \\ \gamma & \text { Gamma function } \\ \mathrm{c} 1 \text { and c2 } & \text { random values taken from } 0 \text { to } 1 \\ \mathrm{r} 1 \text { and } \mathrm{r} 2 & \text { random values taken from } 0 \text { to } 1\end{array}$

